\title{
Trends and outcomes of percutaneous endoscopic gastrostomy in hospitalized patients with malignant and nonmalignant ascites: a nationwide population study
}

\author{
Ishani Shaha, Abhishek Bhurwal ${ }^{\mathrm{b}}$, Harsh Mehtac, Daniel Maas ${ }^{\mathrm{a}}$, Gopala Koneru ${ }^{\mathrm{d}}$, Aaron S. Cohen ${ }^{\mathrm{e}}$, \\ Kambiz S. Kadkhodayan ${ }^{f}$ \\ Creighton University / St. Joseph's Hospital and Medical Center, Phoenix, AZ; Rutgers Robert Wood Johnson \\ University Hospital, New Brunswick, NJ; Saint Barnabas Medical Center, Livingston, NJ; University of Cincinnati, \\ Cincinnati, OH; Valleywise Health, USA
}

\section{Abstract}

Department of a Medicine, Creighton University / St. Joseph's Hospital and Medical Center, Phoenix, AZ (Ishani Shah, Daniel Maas); ${ }^{b}$ Medicine, Division of Gastroenterology (Abhishek Bhurwal); 'Medicine, Saint Barnabas Medical Center, Livingston, NJ (Harsh Mehta); ${ }^{\mathrm{d} M e d i c i n e, ~ U n i v e r s i t y ~ o f ~ C i n c i n n a t i, ~ C i n c i n n a t i, ~ O H ~(G o p a l a ~}$ Koneru); ${ }^{e}$ Gastroenterology, Valleywise Health (Aaron S. Cohen); ${ }^{\mathrm{f}}$ Medicine, Division of Gastroenterology, Creighton University/ St. Joseph's Hospital and Medical Center, Phoenix, AZ (Kambiz S. Kadkhodayan), USA

\section{Conflict of Interest: None}

Correspondence to: Ishani Shah, MD, 350 W Thomas Road, Phoenix, AZ-85013, USA, e-mail: ishani1991@gmail.com

Received 17 April 2020; accepted 15 June 2020; published online 16 September 2020

DOI: https://doi.org/10.20524/aog.2020.0531

\section{Introduction}

Patients with chronic debilitating diseases are often malnourished and require non-oral enteral nutrition with the goal of improving nutritional status as well as quality of life. This is frequently achieved by placement of a gastrostomy tube, which can usually be performed via an endoscopic, radiologic or surgical approach. Most commonly placed in patients with degenerative neurological diseases such as stroke, dementia, amyotrophic lateral sclerosis and Parkinson's disease, a gastrostomy tube is also utilized in conditions associated with esophageal dysmotility [1].

Patients with metastatic cancer and chronic liver disease are malnourished and also commonly require placement of a percutaneous endoscopic gastrostomy (PEG) tube. These 
patient populations often develop significant abdominal ascites from their underlying conditions. This has traditionally been considered an absolute contraindication for PEG tube placement, because of concerns about ascitic fluid leakage and increased risk of infection. To date, there are no studies in the literature that examined the safety of PEG placement in patients with ascites. Therefore, utilizing the Nationwide Inpatient Sample (NIS), we investigated the national temporal trend for PEG tube placement among hospitalized patients. Our primary aim was to determine the outcomes of PEG in patients with ascites, in terms of mortality, length of hospital stay and procedural complications.

\section{Patients and methods}

\section{Data source}

We performed a retrospective analysis using data from the 5-year period from 2010-2014. The NIS is the largest publicly available inpatient healthcare database in the United States. It is maintained by the Healthcare Cost and Utilization Project, sponsored by the Agency for Healthcare Research and Quality. The NIS represents approximately a $20 \%$ sample of all nonfederal hospitals in the US, stratified based upon hospital size, location, geographic region and teaching status. Data from the NIS have been cross-checked against the National Hospital Discharge Survey to verify their reliability [2].

\section{Patient selection and study groups}

Our study population was extracted from the NIS by using the diagnostic and procedure codes of the International Classification of Diseases, Ninth Revision Clinical Modification (ICD-9-CM) (Appendix 1) to identify all patients who underwent PEG tube placement. All patients older than 18 years of age, who underwent PEG tube placement during their hospital stay during the aforementioned study period were identified. These patients were then divided into 2 cohorts. The study group included patients who underwent PEG and had an underlying diagnosis of malignant or non-malignant ascites; the control group included patients who underwent PEG but had no co-diagnosis of either type of ascites.

\section{Outcomes}

Primary outcomes were mortality and length of stay. Secondary outcomes included PEG tube placement-related complications (local infection, procedural hemorrhage, mechanical complications, peritonitis, aspiration pneumonia, esophageal perforation, hemoperitoneum, and gastric prolapse). Additionally, we documented trends of PEG tube placement in patients with a co-diagnosis of ascites over the 5 -year period under consideration.

\section{Statistical analysis}

Data analysis was performed using the STATA 13.0 SE software package (STATA Corp., College Station, TX). Continuous variables were represented as means and standard deviations. These were compared between the study and control groups using the $t$-test or Wilcoxon rank-sum test, as deemed appropriate. Categorical variables were represented as frequencies (percentage) and analyzed using the 2-way chisquare test to compare the 2 groups. Statistical significance (P-value) was assigned at 0.05 . The results were adjusted for age, sex, primary health insurance and medical comorbidities. Multivariate regression was performed to identify ascites as an independent predictive factor of inpatient mortality and length of stay among patients receiving PEG.

\section{Results}

\section{Patient characteristics}

A total of 789,167 patients received PEG tube placement during the 5-year period (2010-2014). Of these, 16,667 (2.11\%) patients had a co-diagnosis of malignant or non-malignant ascites during their hospital stay. The national trends of patients with ascites undergoing PEG remained stable over the 5-year study period $(\mathrm{P}=0.23)$ as shown in Fig. 1.

Patients in the ascites group were younger (mean age 64.12 vs. 69.30 years; $\mathrm{P}<0.001)$ and were more likely to be female $(53.46 \%$ vs. 45.90\%; $\mathrm{P}<0.001)$. No significant racial variations were observed between the 2 groups, a majority of the patients being Caucasian in both $(67.06 \%$ vs. $63.40 \%$; $\mathrm{P}<0.001)$. Patients with ascites had a significantly lower frequency of associated cardiovascular comorbidities, such as hypertension ( $45.66 \%$ vs. $61.59 \%$; $\mathrm{P}<0.001)$, diabetes mellitus (20.94\% vs. $28.61 \%$; $\mathrm{P}=0.002)$, congestive heart failure (CHF) (20.51\% vs. $21.66 \% ; \mathrm{P}=0.12)$, and chronic kidney disease $(\mathrm{CKD})(11.6 \%$ vs. $14.05 \%$; $\mathrm{P}<0.001)$ compared to the control group. As expected, metastatic cancer (34.65\% vs. $6.85 \%$; $\mathrm{P}<0.001)$ and chronic liver disease $(19.85 \%$ vs. $2.04 \% ; \mathrm{P}=0.001)$ were more prevalent among patients in the ascites group. Other demographic factors, such as geographic and regional variations of the population of interest, are listed in Table 1.

\section{Study outcomes}

Patients with ascites receiving PEG had a significantly higher risk of developing peritonitis $(7.52 \%$ vs. $0.72 \% ; \mathrm{P}<0.001)$ compared to patients without ascites. PEG patients with ascites were also more likely to have other complications associated with PEG, such as mechanical dysfunction (2.08\% vs. $1.78 \%$; $\mathrm{P}=0.18$ ) and local infection ( $1.31 \%$ vs. $1.16 \% ; \mathrm{P}=0.45)$; however, these differences were not statistically significant.

Despite having a lower prevalence of cardiovascular comorbidities, such as hypertension, diabetes mellitus, CKD and $\mathrm{CHF}$, patients in the ascites group undergoing PEG had significantly higher all-cause inpatient mortality (16.33\% vs. 


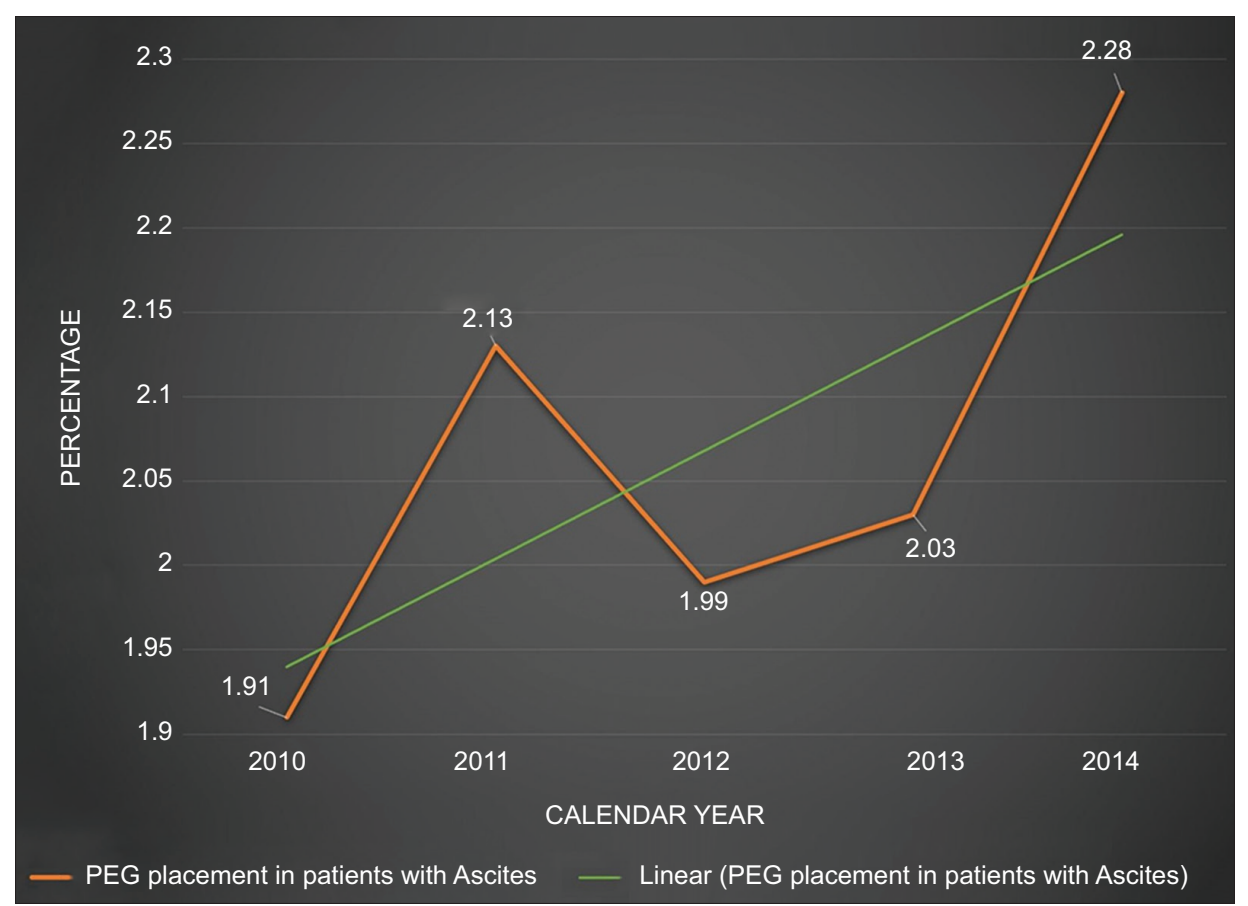

Figure 1 Rates of percutaneous endoscopic gastrostomy (PEG) tube placement in patients with ascites over the period 2010-2014

$7.02 \% ; \mathrm{P}<0.001)$ and longer hospital stays (28.08 vs. 19.45 days; $\mathrm{P}<0.001$ ) as compared to patients in the control group (Table 2).

On multivariate analysis, after adjusting for confounders, ascites was found to be an independent predictor of significantly increased odds of mortality (odds ratio [OR] 2.07, 95\% confidence interval $[\mathrm{CI}] 1.87-2.30 ; \mathrm{P}<0.001)$ and longer hospital stay (OR 0.27, 95\%CI 0.24-0.30; $\mathrm{P}=0.001$ ).

\section{Discussion}

Ascites is defined as accumulation of fluid in the peritoneal cavity that presents as abdominal distension leading to significant abdominal pain, shortness of breath and weight gain. It frequently occurs as a consequence of portal hypertension associated with liver cirrhosis (81\%), followed by malignancy $(10 \%)$, and various other causes such as heart failure (3\%), abdominal tuberculosis (2\%), pancreatic disease (1\%), nephrotic syndrome, peritoneal dialysis, and severe malnutrition, to name a few [3]. Patients with ascites often suffer from malnutrition due to their underlying conditions, most commonly decompensated liver disease and metastatic cancer. Various factors, such as increased satiety from abdominal distension, decreased appetite, altered mentation, recurrent hospitalizations, infections, malabsorption, dietary restrictions, and medications such as lactulose and diuretics, lead to malnutrition in these patients [4]. Those diagnosed with protein-calorie malnutrition from liver cirrhosis have been shown to have increased mortality (14.1\% vs. $7.5 \%$; $\mathrm{P}<0.0001$ ), longer hospital stays (mean 8.7 vs. 5.7 days; $\mathrm{P}<0.0001)$, and higher hospital costs $(\$ 36,818$ vs. $\$ 22,673 ; \mathrm{P}<0.0001)$ compared to the general population $[5,6]$.
Similarly, a majority (50-80\%) of patients with metastatic cancer are known to have severe malnutrition and cachexia, resulting in death (20\%) [7]. Owing to these factors, poor nutritional intake is more detrimental to the health of these patients compared to the general population.

PEG is a relatively common procedure well tolerated in most patients. However, several studies have shown that certain risk factors (hypoalbuminemia, elevated C-reactive protein, low body mass index) and comorbidities (diabetes mellitus and chronic obstructive pulmonary disease) are associated with increased mortality and complications related to PEG tube placement $[8,9]$. Various studies have reported a wide range of complications from PEG tube placement (3-39\%). Minor complications reported include local infection, bleeding, and tube dislodgement; severe complications include aspiration pneumonia, necrotizing fasciitis, buried bumper syndrome, life-threatening hemorrhage, metastatic seeding, peritonitis, bowel perforation, and even death [10-13]. According to a large population-based study, the overall all-cause inpatient mortality of patients undergoing PEG tube placement was $11 \%$ [14]. Another study showed a 30 -day mortality of $43 \%$ after PEG tube placement; however, most deaths were related to the underlying disease process itself, rather than procedural complications from the PEG [15]. This shows that appropriate patient selection is important to prevent such complications.

There are only limited data concerning the safety of PEG placement in patients with abdominal ascites. Procedural difficulties are often attributed to ascites in the placement of PEG tubes, including prevention of proper apposition of the gastric and abdominal walls, impaired tract healing, dislodgement of the catheter due to re-accumulation of ascites, leakage, and increased risk of bleeding and infection [6]. In 2010, Baltz et al evaluated a single-center case series of 26 patients 
Table 1 Baseline characteristics of patients with ascites undergoing placement of a percutaneous endoscopic gastrostomy tube vs. controls

\begin{tabular}{|c|c|c|c|}
\hline Characteristics & $\begin{array}{c}\text { Patients } \\
\text { with ascites } \\
\quad(\%)\end{array}$ & $\begin{array}{c}\text { Patients } \\
\text { without ascites } \\
\text { (\%) }\end{array}$ & P-value \\
\hline Mean age (years) & $64.12 \pm 0.26$ & $69.30 \pm 0.11$ & $<0.001$ \\
\hline $\begin{array}{l}\text { Sex, \% } \\
\text { Male } \\
\text { Female }\end{array}$ & $\begin{array}{l}46.54 \\
53.46\end{array}$ & $\begin{array}{l}54.10 \\
45.90\end{array}$ & $<0.001$ \\
\hline $\begin{array}{l}\text { Race, } \% \\
\text { White } \\
\text { African American } \\
\text { Hispanic }\end{array}$ & $\begin{array}{c}67.06 \\
17.1 \\
8.26\end{array}$ & $\begin{array}{c}63.40 \\
20.35 \\
9.49\end{array}$ & 0.001 \\
\hline $\begin{array}{l}\text { Primary expected payer, } \\
\text { Medicare } \\
\text { Medicaid } \\
\text { Private Insurance }\end{array}$ & $\begin{array}{l}53.87 \\
14.55 \\
26.05\end{array}$ & $\begin{array}{l}68.10 \\
11.56 \\
15.59\end{array}$ & $<0.001$ \\
\hline $\begin{array}{l}\text { Hospital region, \% } \\
\text { Northeast } \\
\text { Midwest } \\
\text { South } \\
\text { West }\end{array}$ & $\begin{array}{l}22.46 \\
21.98 \\
36.23 \\
19.33\end{array}$ & $\begin{array}{c}18.6 \\
22.11 \\
42.19 \\
17.1\end{array}$ & $<0.001$ \\
\hline $\begin{array}{l}\text { Hospital location, \% } \\
\text { Rural } \\
\text { Urban }\end{array}$ & $\begin{array}{c}4.33 \\
95.67\end{array}$ & $\begin{array}{c}6.79 \\
93.21\end{array}$ & $<0.001$ \\
\hline $\begin{array}{l}\text { Comorbidities, \% } \\
\text { Hypertension } \\
\text { DM } \\
\text { CKD } \\
\text { CHF } \\
\text { Metastatic cancer } \\
\text { Chronic liver disease }\end{array}$ & $\begin{array}{c}45.66 \\
20.94 \\
11.6 \\
20.51 \\
34.65 \\
19.85\end{array}$ & $\begin{array}{r}61.59 \\
28.61 \\
14.05 \\
21.66 \\
6.85 \\
2.42\end{array}$ & $\begin{array}{c}<0.001 \\
0.002 \\
<0.001 \\
0.12 \\
<0.001 \\
0.001\end{array}$ \\
\hline
\end{tabular}

DM, diabetes mellitus; $C K D$, chronic kidney disease; $C H F$, congestive heart failure

with cirrhosis and found that the mortality rate of PEG tube placement in cirrhotic patients (65\% of whom had ascites) was about $38-42 \%$. While $53 \%$ of patients with ascites died within the first 30 days, only 2 of these patients died from procedural complications, including aspiration pneumonia and new onset peritonitis, after the procedure [16]. It thus becomes difficult to ascertain whether the high mortality could be attributed to complications from PEG placement in the presence of ascites or to the underlying disease process, knowing that most patients with advanced liver disease are significantly debilitated.

Case reports have previously been published about successful PEG tube placement in ascitic patients using various technical improvisations. Preprocedural large-volume paracentesis in combination with aggressive diuresis has been described for successful PEG placement in patients with cirrhosis and malignancy-related ascites $[17,18]$. In another case series, PEG was placed using the pull-through technique, followed by placement of 3-suture gastropexy for prevention of ascitic fluid leakage [19]. The use of gastropexy for PEG placement in patients with intraperitoneally interposed organs has also been described in various reports $[20,21]$. It is interesting to note
Table 2 Primary and secondary outcomes of patients with ascites undergoing placement of a percutaneous endoscopic gastrostomy (PEG) tube vs. controls

\begin{tabular}{|c|c|c|c|}
\hline Outcomes & $\begin{array}{c}\text { Patients } \\
\text { with ascites } \\
\text { (\%) }\end{array}$ & $\begin{array}{c}\text { Patients } \\
\text { without ascites } \\
(\%)\end{array}$ & P-value \\
\hline \multicolumn{4}{|l|}{ Complications of PEG, \% } \\
\hline Peritonitis & 7.52 & 0.72 & $<0.001$ \\
\hline Aspiration pneumonia & 20.41 & 2.69 & $<0.001$ \\
\hline Mechanical dysfunction & 2.08 & 1.78 & 0.18 \\
\hline Local infection & 1.31 & 1.16 & 0.45 \\
\hline Hemoperitoneum & 0.72 & 0.19 & $<0.001$ \\
\hline Gastric prolapse & 0.2 & 0.17 & 0.67 \\
\hline Esophageal perforation & 0.15 & 0.47 & $<0.001$ \\
\hline Procedural hemorrhage & 1.69 & 0.91 & $<0.001$ \\
\hline Mean length of stay (days) & 28.08 & 19.45 & 0.001 \\
\hline In-hospital mortality, \% & 16.33 & 7.02 & $<0.001$ \\
\hline
\end{tabular}

that a combination of large-volume paracentesis followed by PEG with gastropexy has also popularly been employed for placement of interventional radiology-guided gastrostomy tubes in patients with voluminous ascites [22-24]. While paracentesis helps with prevention of ascitic fluid leakage, gastropexy helps prevent PEG tube dislodgement. Success rates as high as $97.8 \%$ have been reported in these studies [24].

We believe that our study is a comprehensive representation of prevalence, demographic characteristics, procedural complications, mortality, and length of stay among the largest ever patient population with ascites undergoing PEG tube placement. Our study shows that PEG continues to be a high-risk procedure in these patients. The presence of ascites was associated with significantly higher odds of mortality and of peritonitis among patients undergoing PEG compared to non-ascitic patients. Additionally, our study showed that the presence of ascites was associated with a greater independent risk of mortality among patients undergoing PEG placement. This finding is helpful in overriding any confounders that could have led to falsely elevated all-cause mortality among patients with ascites undergoing PEG. In other words, although it is possible that the patients with ascites could be sicker because of their underlying condition, accounting for their higher all-cause mortality, ascites was shown to be an independent risk factor associated with increased odds of death in our study. These results are in concordance with conventional practices, where ascites is considered a contraindication to PEG placement in most cases. Another study using the NIS showed that, although associated with a higher rate of complications, the presence of ascites among cirrhotic patients was associated with lower all-cause mortality as compared to cirrhotic patients without ascites [25]. Unlike this study, where only patients with cirrhosis-associated ascites were taken into consideration, our study analyzed the outcomes of PEG among all patients with ascites, irrespective of the underlying cause, over a much longer time period. These factors account for the larger size of our study population and may possibly explain the discrepancy between the 2 studies' results.

Several limitations of this study should be acknowledged. Since all data were obtained from the NIS database, the 
identification of various associated complications and comorbidities is highly dependent on the accuracy of coding procedures. We were also unable to quantify the amount of ascitic fluid present in these patients, or to determine whether paracentesis was performed prior to PEG placement, making it hard to analyze whether paracentesis helps with reducing the rate of complications and mortality. However, it is important to note that the NIS has been extensively validated over the years and that any misclassification occurring from inaccuracies in ICD-9-CM codes would probably be distributed uniformly over the entire nation's population, allowing for data generalizability.

In conclusion, our study recommends against the placement of PEG tubes in patients with ascites. It is, however, important to note that, despite the higher odds of complications and mortality, a significantly large number of patients with ascites continued to receive PEG over the 5-year study period. We believe that mindful patient selection and meticulous contemplation of the various risks and benefits of PEG in each patient are imperative for minimizing complications and optimizing nutrition in this high-risk patient population.

\section{Summary Box}

\section{What is already known:}

- Most patients with ascites as well as these underlying conditions are nutritionally deprived and may require long-term enteral feeding via a percutaneous endoscopic gastrostomy (PEG) tube

- The presence of ascites has, however, been deemed to be a relative contraindication to PEG tube placement, because of the risk of spillage and superimposed infection of ascetic fluid, which could lead to life-threatening peritonitis, septic shock, and death; it could also lead to tracking of cancer cells and iatrogenic spread of malignancy

\section{What the new findings are:}

- Although the risk of PEG-related complications continues to be significantly prevalent in a nationally representative population sample, more people with underlying ascites are getting a PEG over the years

\section{References}

1. Friginal-Ruiz AB, Lucendo AJ. Percutaneous endoscopic gastrostomy: a practical overview on its indications, placement conditions, management, and nursing care. Gastroenterol Nurs 2015;38:354-366.

2. Whalen D, Houchens R, Elixhauser A, 2003 HCUP Nationwide Inpatient Sample (NIS) Comparison Report. HCUP Method Series Report \# 2006-09. Online December 1, 2006. U.S. Agency for Healthcare Research and Quality. Available from: http://www.hcup-us. ahrq.gov/reports/methods/methods_topic.jsp [Accessed 14 July 2020].

3. Runyon BA. Management of adult patients with ascites caused by cirrhosis. Hepatology 1998;27:264-272.

4. Verslype C, Cassiman D. Cirrhosis and malnutrition: assessment and management. Acta Gastroenterol Belg 2010;73:510-513.

5. Sam J, Nguyen GC. Protein-calorie malnutrition as a prognostic indicator of mortality among patients hospitalized with cirrhosis and portal hypertension. Liver Int 2009;29:1396-1402.

6. Vance I, Shah, N. High risk percutaneous endoscopic gastrostomy tubes: issues to consider. Pract Gastroenterol 2012;36:28-40.

7. Ryan AM, Power DG, Daly L, Cushen SJ, Ní Bhuachalla, Prado CM. Cancer-associated malnutrition, cachexia and sarcopenia: the skeleton in the hospital closet 40 years later. Proc Nutr Soc 2016;75:199-211.

8. Lang A, Bardan E, Chowers Y, et al. Risk factors for mortality in patients undergoing percutaneous endoscopic gastrostomy. Endoscopy 2004;36:522-526.

9. Lee C, Im JP, Kim JW, et al; Small Intestine Research Group of the Korean Association for the Study of Intestinal Disease (KASID). Risk factors for complications and mortality of percutaneous endoscopic gastrostomy: a multicenter, retrospective study. Surg Endosc 2013;27:3806-3815.

10. Blomberg J, Lagergren J, Martin L, Mattsson F, Lagergren P. Complications after percutaneous endoscopic gastrostomy in a prospective study. Scand J Gastroenterol 2012;47:737-742.

11. Larson DE, Burton DD, Schroeder KW, DiMagno EP. Percutaneous endoscopic gastrostomy. Indications, success, complications, and mortality in 314 consecutive patients. Gastroenterology 1987;93:48-52.

12. Rahnemai-Azar AA, Rahnemaiazar AA, Naghshizadian R, Kurtz A, Farkas DT. Percutaneous endoscopic gastrostomy: indications, technique, complications and management. World $J$ Gastroenterol 2014;20:7739-7751.

13. Schneider AS, Schettler A, Markowski A, et al; ${ }^{\star}$ Conference presentation: 36th ESPEN Congress in Leipzig, Germany on August 31st - September 3rd, 2013. Complication and mortality rate after percutaneous endoscopic gastrostomy are low and indication-dependent. Scand J Gastroenterol 2014;49:891-898.

14. Arora G, Rockey D, Gupta S. High In-hospital mortality after percutaneous endoscopic gastrostomy: results of a nationwide population-based study. Clin Gastroenterol Hepatol 2013;11:1437-1444.

15. Johnston SD, Tham TC, Mason M. Death after PEG: results of the National Confidential Enquiry into Patient Outcome and Death. Gastrointest Endosc 2008;68:223-227.

16. Baltz JG, Argo CK, Al-Osaimi AM, Northup PG. Mortality after percutaneous endoscopic gastrostomy in patients with cirrhosis: a case series. Gastrointest Endosc 2010;72:1072-1075.

17. Kynci JA, Chodash HB, Tsang TK. PEG in a patient with ascites and varices. Gastrointest Endosc 1995;42:100-101.

18. Pothuri B, Montemarano M, Gerardi M, et al. Percutaneous endoscopic gastrostomy tube placement in patients with malignant bowel obstruction due to ovarian carcinoma. Gynecol Oncol 2005;96:330-334.

19. Wejda BU, Deppe H, Huchzermeyer H, Dormann AJ. PEG placement in patients with ascites: a new approach. Gastrointest Endosc 2005;61:178-180.

20. Moriwaki Y, Otani J, Okuda J, et al. Successful nutritional support for a dysphagic patient with massive cirrhotic ascites and intrathoracic stomach using percutaneous endoscopic gastrostomy (PEG). Nutrition 2014;30:1456-1459.

21. Moriwaki Y, Otani J, Okuda J, Zotani H, Kasuga S. Percutaneous sonographically assisted endoscopic gastrostomy for difficult cases with interposed organs. Nutrition 2018;54:100-104.

22. Lee MJ, Saini S, Brink JA, Morrison MC, Hahn PF, Mueller PR. Malignant small bowel obstruction and ascites: not a contraindication to percutaneous gastrostomy. Clin Radiol 1991;44:332-334.

23. O'Connor OJ, Diver E, McDermott S, et al. Palliative gastrostomy in the setting of voluminous ascites. J Palliat Med 2014; 17:811-821.

24. Ryan JM, Hahn PF, Mueller PR. Performing radiologic gastrostomy or gastrojejunostomy in patients with malignant ascites. AJR Am J Roentgenol 1998;171:1003-1006.

25. Al-Abboodi Y, Ridha A, Fasullo M, Naguib TH. Risks of PEG tube placement in patients with cirrhosis-associated ascites. Clin Exp Gastroenterol 2017;10:211-214. 


\section{Supplementary material}

Appendix 1

\begin{tabular}{|c|c|}
\hline Diagnosis/procedure name & ICD-9 code \\
\hline PEG & 43.11 \\
\hline Ascites & $789.59,789.51$ \\
\hline Chronic liver disease & 571.x, 572.x \\
\hline Metastatic cancer & $\begin{array}{l}\text { 196.x, 197.x, 198.x, 199.x, 789.51, } \\
\text { 209.7x }\end{array}$ \\
\hline Hypertension & 401.x, 402.x, 403.x, 404.x, 405.x \\
\hline Diabetes mellitus & 250.x \\
\hline Chronic kidney disease & $585 . \mathrm{x}$ \\
\hline Congestive heart failure & 428.x \\
\hline Peritonitis & $567.2 \mathrm{x}$ \\
\hline Local infection of PEG & 536.41 \\
\hline Mechanical dysfunction of PEG & 536.42 \\
\hline Hemoperitoneum & 568.81 \\
\hline Gastric prolapse & 530.4 \\
\hline Aspiration pneumonia & 507.0 \\
\hline Esophageal perforation & 537.89 \\
\hline
\end{tabular}

PEG, percutaneous endoscopic gastrostomy 